\title{
Virtual Reality as a Training Tool for the Development of Ice Hockey Thinking
}

\author{
Pavla Satrapová, Tomáš Perič and Adam Rulík \\ Charles University, Faculty of Physical Education and Sport, Prague, Czech Republic
}

\begin{abstract}
Virtual reality is becoming an important part of sports training in all age and performance categories. The research group consisted of 197 ice hockey players aged thirteen to fifteen. All probands performed eight tests in virtual reality, the initial four focusing on cognitive functions and the remaining four on ice hockey-specific game skills. The strongest correlations were found between variables best solution and correct decision (0.87) and accurate pass 2 and pass success (0.91). The strongest correlation between main variables was discovered between correct decision and looking for open lanes (0.60). Strong relationships of partial correlations were also found between correct decision and looking for open lanes (0.58) and time to play the puck and time movement anticipation (0.43). Based on the findings in five key variables, three being game skills (time to play the puck, spatial orientation, looking for open lanes) and two being cognitive skills (time movement anticipation, multiple object tracking), it is possible to say that virtual reality can be used as a training tool for specific ice hockey training, especially for measuring specific ice hockey thinking.
\end{abstract}

Keywords: interactive virtual reality, ice hockey thinking, cognitive development, ice hockey

\section{Introduction}

Initially, virtual reality was used mainly in the entertainment industry. With the development and improvement of software and hardware, virtual reality started to emerge in sports disciplines as well, and it is one of the fastest-spreading technologies of today. At the most general level, virtual reality is understood as a three-dimensional environment modelled and processed by a computer. A user perceives a computer simulation of a realistic looking, illusory 3D setting as a real environment that enables them to interact with it (Human - computer interaction - HCI). In a virtual world, the human is represented by a virtual identity (a so-called "avatar" - a graphic representative of the user in virtual reality). In relation to sports, we can define virtual reality as an instance where users are involved in a sport represented in a simulated environment, in order to create the notion of being in a different environment both mentally and physically. This allows for an interaction with said environment (Neumann et al., 2018). The use of virtual reality in sports can be then defined as a situation, in which the user is involved in a sport in a PC-simulated environment with the aim of creating a feeling of mental and physical presence in this setting and enabling an interaction with it (Alhadad a Abood, 2018). Three basic approaches to interaction in virtual reality can be distinguished: 


\section{$4^{\text {th }}$ International Conference on Advanced Research in Teaching and Education}

a) Passive - The user cannot change or affect anything. An example can be watching a movie or reading a book.

b) Active - The user has the possibility to affect their own movement, but cannot shape and affect the environment. A typical example is a $360^{\circ}$ video where the athlete goes through e.g. opponent's game variants in sports matches.

c) Interactive - The user can form the surrounding world, take objects in hands and work with them. An example can be exercises for technique or cognitive processes development.

In sports training, the mainly used forms are active and interactive.

There are three main advantages of virtual reality in sports.

1. The first advantage stated by Bideau et al. (2010) is that in a virtual reality setting, the subject (a forward) and a virtual object (a "simulated" defender) can interact while the experimenter is managing and editing the type of information the player (tested subject) can see in any given moment.

2. The second advantage lies in the possibility to control and optimize all factors affecting player's decisions. This ensures that each run is completely reproducible.

3. The last advantage is a real-time observation of tested subject's head movement during the testing. Thanks to this, scientists can update player's virtual view in real time, which helps to improve player's feelings in reality. Images in virtual reality are stereoscopic and provide the player with a significant depth of information. Due to these reasons, player's behaviour and perception in virtual reality is much closer to their behaviour and perception in the real world (Bideau et al.. 2010).

In 2003, a study by Bideau et al. enabled to validate virtual reality as a way to examine (test) preliminary reactions (anticipation responses) of elite handball players. Other authors that wanted to use virtual reality in their study, this time regarding football players, were Craig et al. (2006).

If we want to use virtual reality for improvements in sport performance or for movement anticipation, we need to better understand the "perception-action cycle" that the athlete makes. A video recording does not enable this due to its own limits. In other words, it does not allow going into depth and analysing the perception cycle. Thanks to a more thorough utilization of virtual reality, a study of Bideau et al. (2010) focused on the effect of perception on a movement selection (reaction; the movement that the player performs), and how these choices affect perception afterwards. The authors examined which perceptual information is important. After that, they created a framework of situations, which they used for two studies:

1) The first situation involved only a perception in rugby - to evaluate and detect a misleading movement of a forward.

2) The second situation required a perception of action in handball. The task performed was to analyse the reaction of a goalkeeper to a different trajectory of the ball (perception).

These two case studies prove advantages of virtual reality for a better understanding of the "perception cycle", and thus enable to analyse the sport performance.

The use and settings of virtual reality technology for analysing sport performance involved three steps.

1) The first step was capturing the motion of an athlete in particular sport. Not only are these actions useful for animations in virtual reality, they also provide a comparison of subject's movement in real world and in virtual reality. 


\section{$4^{\text {th }}$ International Conference on Advanced Research in Teaching and Education}

2) The second step focused on animation of human movement in virtual reality and adjusting it to specific limitations of virtual reality.

3) The third step involved a presentation of moves in a virtual environment.

Although the first two steps are common for all technologies, the third step depends on specific application (technology), as every virtual software has its own strengths and weaknesses.

An example of this is the study with handball goalkeepers, where subjects had to act as in the real world and needed a space for a free movement. The authors therefore opted for a large cylinder screen surrounding the user. On the other hand, the subject in the rugby case study was only identifying its virtual opponent and his deceptive moves. The authors thus used a display placed on the head (HMD). To capture the motion, they used Vicon Motion Analysis System (by Oxford Metrics), which records the athlete's movement in the real world. The recording of players allowed for a deep retrospective biomechanical movement analysis, which showed what (which move) will the forward do to successfully bypass the defender. For the handball case study, authors captured the motion of twelve players and placed additional marks on the ball to capture its trajectory as well.

The use of virtual reality in the rugby case study proved that league players are able to define the final move (direction) of the forward faster than beginners. In the handball case study, the authors evaluated the skill of anticipation using a success rate and time required. Case studies that involved ball trajectory provided a higher percentage of successful reactions.

Vignais et al. (2015) then studied the comparison between the use of video and virtual reality for an analysis of visual information in a particular sport situation. The comparison between a video clip and virtual reality was performed on handball goalkeepers, which were given two tasks. A so-called unconnected task, where the keeper is shown the final destination of the ball, and a so-called connected task, where keepers try to catch the ball in a virtual reality setting. The results of this study proved that goalkeepers were more successful and managed to catch the ball (and thus predict its trajectory) better in a virtual reality than with a video clip.

Another sport where virtual reality was used in research is football. The system CopeFoot designed by De Loor et al. (2008) is supposed to help players learn tactical football decisions and put them into practice. CopeFoot uses contextual reasoning as an educational platform where a player competes or cooperates with an "avatar". The avatar perceives, creates and responds to situations on a football pitch. The avatar for CopeFoot was created and designed to mimic the process of an elite player's decision-making in a real context. In 2011, Bossard et al. picked twelve experienced young football players. Their task was to perform five counterattacks from the middle of the field with two forwards and three defenders. The authors created decision-making models based on objective observations and follow-up interviews with players about solutions of situations from a tactical perspective. These models (patterns) of decision-making were applied in a sequential scenario as well as the CopeFoot system, which were used to train and program the avatar. In the CopeFoot system, the avatar faces and solves tactical problems and interacts with the player, thus jointly creating relevant solutions to these situations. However, one disadvantage of the system prevails, because the effect of training connecting cognitive (tactical solutions) and kinetic operations (carrying out tactical moves) remains unknown.

Virtual reality does not emerge only in team sports. The goal of one study in rowing was to test the performance, motivation and emotional impact on aerobic exercise in virtual reality, where an individual trains alone or with other people (rivals). The group training in virtual reality demonstrated a better output performance than the group that did not train in virtual reality. 


\section{$4^{\text {th }}$ International Conference on Advanced Research in Teaching and Education}

Despite this fact, participants in virtual reality did not feel like they made more physical effort and deemed the ride more pleasant in comparison to those that did not ride in virtual reality. The conclusion is that virtual reality improves the performance and emotional response to aerobic exercise. Performance effects are also fostered by the presence of other riders in virtual reality (Murray et al., 2015).

The use of virtual reality in physical education is discussed as well. A study by Pasco, D. (2013) predicts a more effective utilization of virtual reality to support physical education (physical activity), thus pushing for conceptual changes in the teaching of physical education.

\section{Body of paper}

\subsection{Formulating the problem}

Very little is known about the use of virtual reality in sports so far, mainly in its use for a specific sports training, which is especially true for ice hockey. Is it therefore possible to use virtual reality for ice hockey training? One component of the technical-tactical element is also the so-called specific ice hockey thinking. This aspect is easily observable in player's game performance, but as of today there is no way to measure and define it in exact values. Is the specific ice hockey thinking measurable at all, and could the tool for its assessment be a virtual reality program?

\subsection{Aim of the work}

The aim of this work is to discover the relations between variables consisting of selected game skills and cognitive skills.

\subsection{Research methodology}

The research is designed as a correlation research with the aim of detecting connections between variables. By using a correlation research method, a relationship degree (relationship closeness) between two variables will be determined. Connections and the relationship closeness will be expressed by correlations.

The testing took place in a virtual reality laboratory. At the beginning, players with no prior experience with virtual reality were acquainted with the laboratory equipment. After that, each proband was briefly introduced with the content of the testing and controls of the program used. Before the start of the testing itself, there was always a period for orientation in the virtual setting. The testing involved four tests of cognitive functions and four tests of game skills, hence eight tests in total taking approximately forty-five minutes altogether. Before each individual test, probands were explained its content and principle once more, or they were played a short instructional video directly in the program. The test was never started before the player fully understood it. The player had three attempts for each test. One shortened attempt to try the test, which was not counted into the results, and two measured ninety-second attempts. The break between the attempts was individual. Before the tests of game skills, the proband was handed a pair of hockey gloves and they had the floor calibrated with a special hockey stick for a maximum testing objectivity.

Variables were defined based on literature research and the work of Rulík (2020). The main variables are selected game skills and cognitive functions. Among game skills, experts 


\section{$4^{\text {th }}$ International Conference on Advanced Research in Teaching and Education}

distinguish release time, spatial orientation, looking for open lanes, verbal communication and correct decision. Cognitive functions consist of recognition time, multiple objects tracking, detail recognition, time movement anticipation and peripheral vision. All these variables contain partial variables, which then form main variables. Main variables can comprise one to four partial variables.

a) Game variables $=$ game reading

- release time (time to play the puck),

- spatial orientation (rapid shot + pass success),

- looking for open lanes (shot on goal, best solution, utilization of open lanes),

- $\quad$ verbal communication (correct request for a pass)

- correct decision (ice hockey intelligence)

Img. 1 - Ice hockey variables
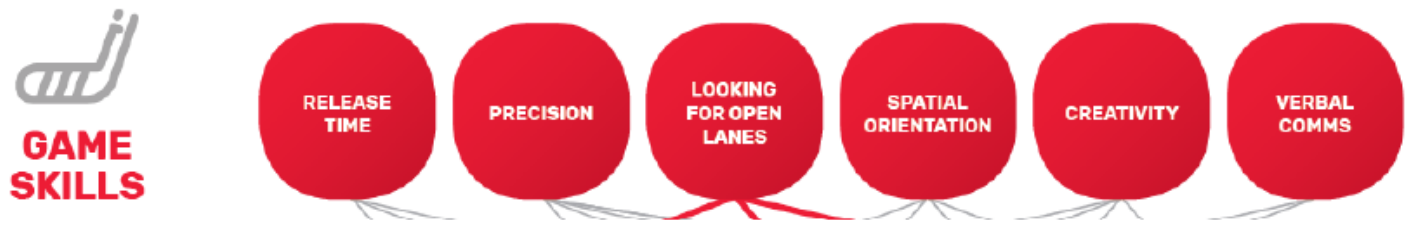

Source: Sense Arena

b) Cognitive variables $=$ decision-making

- recognition time (average time between touches of the puck, recognition time, average time for passing),

- multiple objects tracking (correct pass, accurate pass),

- detail recognition (accurate pass),

- time movement anticipation (correct pass),

- peripheral vision (playing field coverage).

Img. 2 - Cognitive variables
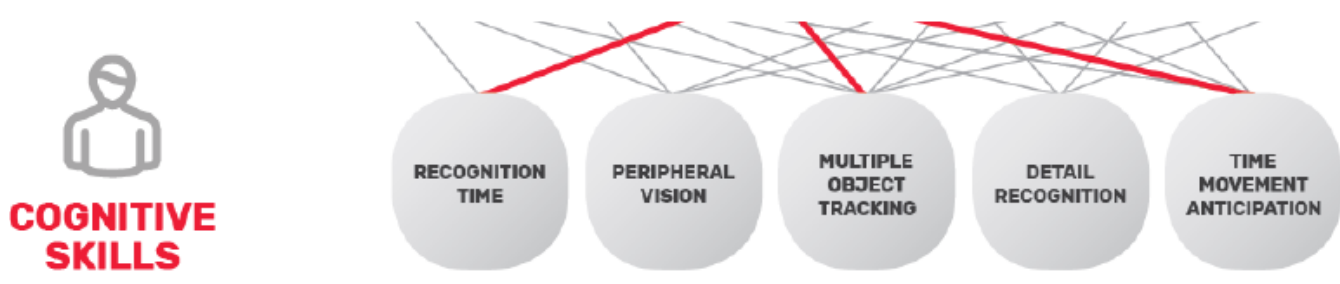

Source: Sense Arena

Img. 3 - Set of main variables linking game skills (game reading) and cognitive skills (decision-making) 


\section{$4^{\text {th }}$ International Conference on Advanced Research in Teaching and Education}
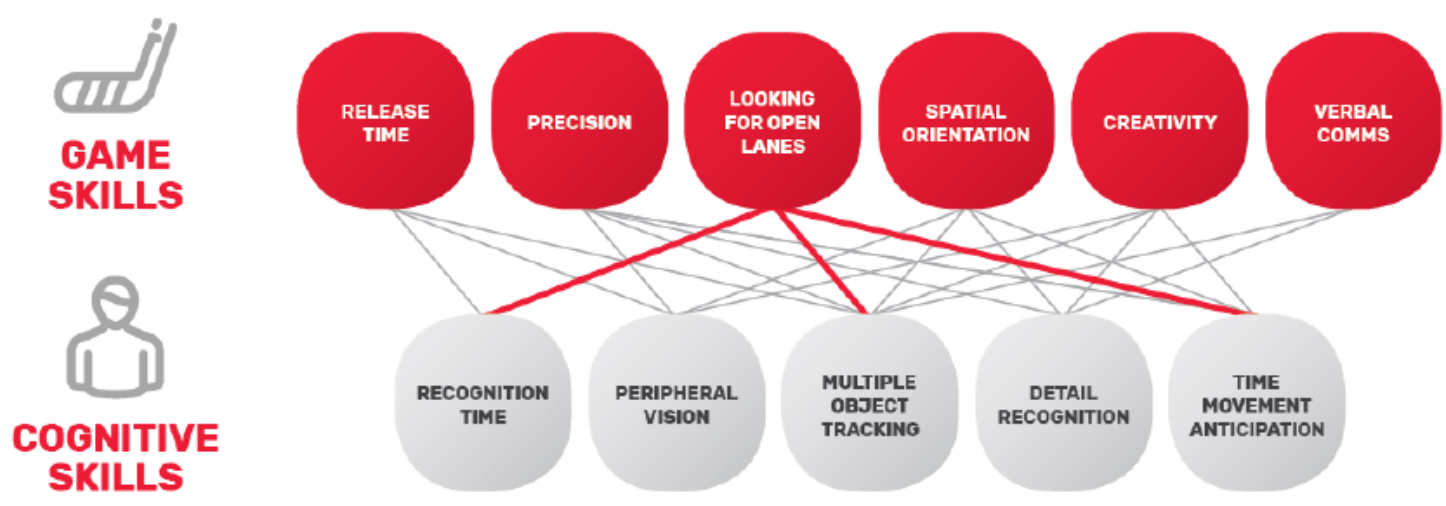

Source: Sense Arena

Game reading

Img. 4 - Game reading variables

\section{MULTIPLE OBJECT TRACKING}

The ability to track multiple objects and act accordingly

DETAIL RECOGNITION

Recognition to detail in order to play effectively

TIME-MOVEMENT ANTICIPATION

Anticipation of a moving object trajectory in time

PERIPHERAL VISION

The ability to have maximum objects in the field of view

LOOKING FOR OPEN LANES

The ability to create a play for teammates or score

Source: Sense Arena
Decision-making

Img. 5 - Decision-making variables

REACTION TIME
Time from a stimuli to the first move
RELEASE TIME
The time from receiving to releasing the puck
SPATIAL ORIENTATION
The ability to play w/o the puck in an effective way
CORRECT DECISION
The hockey decision making
VERBAL COMMUNICATION
The ability to yell for a pass when open

\section{Ice hockey-specific game skills}

Release time

Release time is the time in which the player is able to solve the situation and play the puck. It is measured from the moment of receiving the puck to the moment of playing it. This variable is a percent form of a partial variable release time in milliseconds.

Spatial orientation

In ice hockey, spatial orientation relates to perception of teammates and opponents. This variable is expressed by the ability to play effectively without the puck, e.g., for how many passes the player can make themselves available and shoot within a certain timeframe. Hence, partial variables of spatial orientation, rapid shot and pass success are derived from it. Rapid shot is the number of shots fired within half a second after receiving the puck, and pass success the number of passes for which the player can make themselves available and receive them. 


\section{$4^{\text {th }}$ International Conference on Advanced Research in Teaching and Education}

Looking for open lanes

This variable determines whether the player is able to find space for a pass or a shot, and perform it in the right moment without it being interfered by an opponent. Partial variables are shots on goal, best solution, passes not captured and utilization of open lanes. Shots on goal describe the number of shots placed within half of a meter of the goal. Best solution is the number of situations solved in the best possible way. Passes not captured and utilization of open lanes are expressed by their number.

Verbal communication

Verbal communication assesses whether the player communicates with their teammates loud enough and at the right time. A partial variable is correct request for a pass, which is determined by right calls in situations where the player is available.

\section{Correct decision}

The factor evaluated is whether the player keeps finding the correct and original solutions to situations and is able to use different solutions variably. A partial variable of correct decision is called ice hockey intelligence, which expresses the number of situations solved the right way.

\section{Cognitive skills}

Recognition time

Recognition time expresses show long does it take the player to assess and solve the situation at hand. Partial variables are average time between touches of the puck in milliseconds, recognition time in milliseconds and average time for passing, which is the time in which the player can assess the situation and pass the puck.

Multiple objects tracking

Multiple objects tracking is the ability to track multiple objects at once and react to them. Partial variables are correct pass and accurate pass 2. Correct pass expresses the number of passes sent to the player and accurate pass 2 the number of passes heading directly to the blade of others' stick.

Detail recognition

This factor describes recognition of detailed elements that are important in order to play effectively. A partial variable is accurate pass, which is the number of passes placed within 60 centimetres from the centre of the blade.

Time movement anticipation 


\section{$4^{\text {th }}$ International Conference on Advanced Research in Teaching and Education}

Also simply ,anticipation“, it is the player's readiness to react and address situations in advance by anticipating e.g. a puck trajectory. A partial variable is correct pass, which is expressed as the number of passes sent to the player.

Peripheral vision

This variable expresses the ability to perceive the maximum number of objects in the field of view. A partial variable is playing field coverage, which is the time in seconds during which the player has other players in the field of view.

\subsection{Statistical evaluation}

To evaluate results and compare main variables, a correlation matrix was used together with creating graphics in the statistical software " $R$ ". Partial correlations were used as well, and showed the dependency of one variable on another while eliminating effects of other variables. Laterality index of variables was also calculated, and turned out to be a key part of the evaluation.

\subsection{Results}

Values between 0.44 to 0.53 were moderate correlations. These are correlation relationship between the variables pairs looking for open lanes and time movement anticipation, spatial orientation and multiple objects tracking, time movement anticipation and multiple objects tracking, and spatial orientation and release time.

A strong correlation was found between correct decision and looking for open lanes with the value of 0,58 .

Chart 1 - Correlations of main variables

\begin{tabular}{|c|c|c|c|c|c|c|c|c|}
\hline & REL.T. & so & vc & LOL & $C D$ & DC & REC.T. & TMA \\
\hline REL.T. & 1 & 0,44 & $-0,27$ & 0,37 & 0,08 & $-0,06$ & 0,20 & 0,37 \\
\hline so & 0,44 & 1 & $-0,13$ & 0,23 & 0,01 & 0,08 & 0,25 & 0,30 \\
\hline VC & $-0,27$ & $-0,13$ & 1 & $-0,07$ & 0,00 & 0,00 & $-0,01$ & $-0,16$ \\
\hline LOL & 0,37 & 0,23 & $-0,07$ & 1 & 0,58 & 0,09 & 0,15 & 0,53 \\
\hline$C D$ & 0,08 & 0,01 & 0,00 & 0,58 & 1 & 0,09 & 0,06 & 0,22 \\
\hline DC & $-0,06$ & 0,08 & 0,00 & 0,09 & 0,09 & 1 & $-0,02$ & 0,17 \\
\hline REC.T. & 0,20 & 0,25 & $-0,01$ & 0,15 & 0,06 & $-0,02$ & 1 & 0,24 \\
\hline TMA & 0,37 & 0,30 & $-0,16$ & 0,53 & 0,22 & 0,17 & 0,24 & 1 \\
\hline Мот & 0,26 & 0,52 & $-0,08$ & 0,37 & 0,25 & 0,29 & 0,21 & 0,44 \\
\hline PV & 0,37 & 0,25 & $-0,03$ & 0,34 & 0,21 & 0,13 & 0,06 & 0,24 \\
\hline
\end{tabular}

highlighted correlations are statistically

significant at the $5 \%$ level of significance 


\section{$4^{\text {th }}$ International Conference on Advanced Research in Teaching and Education}

MOT - multiple objects tracking

$D C$ - detail recognition

TMA - time movement anticipation

REC.T. - recognition time

\author{
REL.T. - release time \\ $V C$ - verbal communication \\ $L O L$ - looking for open lanes \\ $C D$ - correct decision
}

The relationship between correct decision and looking for open lanes, which was the strongest, is linked by a partial variable ice hockey intelligence. Ice hockey-specific intelligence is closely linked to both main variables. Simply said, it is measured by the percentage of cases where the player made a right decision and created an opportunity for a teammate.

Moderate correlations between the variables looking for open lanes and time space anticipation were not a surprise. If a player is able to anticipate a certain situation as well as movement of teammates and opponents, they are always one step ahead. It is also easier for the player to look for open lanes and opporunities for passes. Other moderate correlations showed up between spatial orientation and multiple objects tracking, and time movement anticipation and multiple objects tracking. With a good orientation in space, a player is able to make the right choice about picking a spot, timing moves and passes, tracking of teammates, opponents, goalkeepers and the puck. They can thus track multiple objects and therefore anticipate situation and movement in time and space. The last moderate correlation was identified between spatial orientation and release time. If a player can orientate themselves in time and space, they can choose the right time to play the puck, either shooting or passing.

\subsubsection{Correlations of game skills and cognitive skills}

Chart 2 - Correlations of game skills and cognitive skills

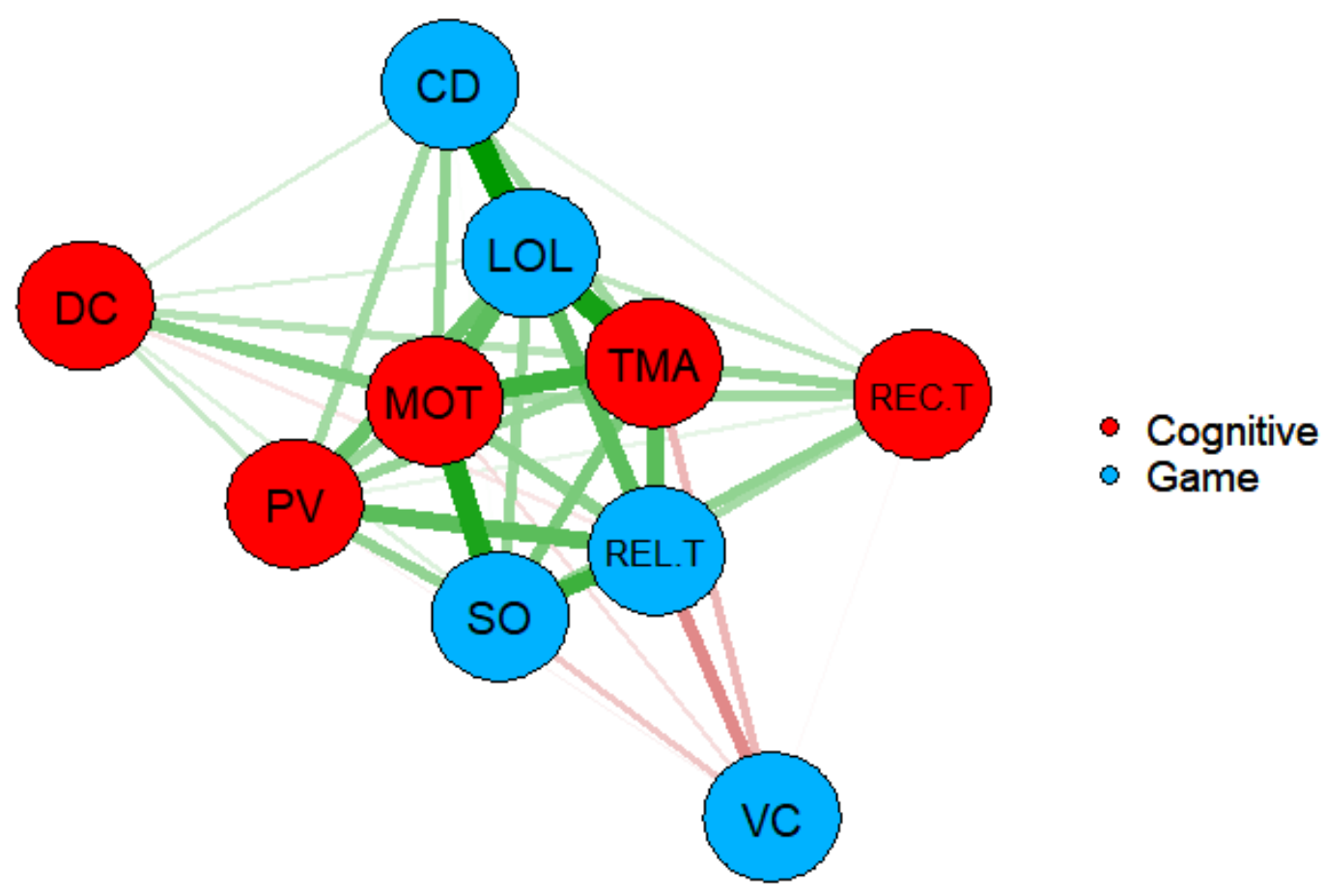




\section{$4^{\text {th }}$ International Conference on Advanced Research in Teaching and Education}

Cognitive skills

$P V$ - peripheral vision

MOT - multiple objects tracking

$D C$-detail recognition

TMA - time movement anticipation

REC.T. - recognition time
Game skills

$S O$ - spatial orientation

REL.T. - release time

$V C$ - verbal communication

$L O L$ - looking for open lanes

$C D$ - correct decision

A strong relationship was identified between release time and time space anticipation, which makes sense, as a player who is a skilled anticipator can determine the best time to release the puck. Another logical, strong relationship showed up between spatial orientation and multiple objects tracking. A player with a good orientation in space can perceive and watch multiple objects at once. A third strong relationship turned out between looking for open lanes and time movement anticipation. The relationship between release time and peripheral vision can also be marked as a strong one.

Weaker relationships were identified between looking for open lanes and recognition time, and between spatial orientation and peripheral vision. Relationships between recognition time and correct decision and between correct decision and detail recognition were very weak.

\subsubsection{Partial correlations}

Chart 3 - Partial correlations

\begin{tabular}{|c|c|c|c|c|c|c|c|c|}
\hline & REL.T. & so & vc & LOL & $C D$ & DC & REC.T. & TMA \\
\hline REL.T. & 1 & 0,28 & $-0,26$ & 0,24 & $-0,16$ & $-0,17$ & 0,10 & 0,07 \\
\hline so & 0,28 & 1 & $-0,03$ & 0,12 & $-0,18$ & $-0,07$ & 0,11 & $-0,11$ \\
\hline vc & $-0,26$ & $-0,03$ & 1 & 0,09 & $-0,03$ & $-0,03$ & 0,08 & $-0,13$ \\
\hline LOL & 0,24 & 0,12 & 0,09 & 1 & 0,58 & 0,04 & 0,00 & 0,39 \\
\hline$C D$ & $-0,16$ & $-0,18$ & $-0,03$ & 0,58 & 1 & $-0,04$ & 0,02 & $-0,13$ \\
\hline DC & $-0,17$ & $-0,07$ & $-0,03$ & 0,04 & $-0,04$ & 1 & $-0,06$ & 0,03 \\
\hline REC.T. & 0,10 & 0,11 & 0,08 & 0,00 & 0,02 & $-0,06$ & 1 & 0,17 \\
\hline TMA & 0,07 & $-0,11$ & $-0,13$ & 0,39 & $-0,13$ & 0,03 & 0,17 & 1 \\
\hline Мот & $-0,03$ & 0,43 & 0,00 & 0,00 & 0,18 & 0,26 & 0,04 & 0,26 \\
\hline PV & 0,27 & 0,09 & 0,09 & 0,05 & 0,10 & 0,15 & $-0,05$ & 0,02 \\
\hline & $* p<0,05$ & & \multicolumn{4}{|c|}{$\begin{array}{l}\text { highlighted correlations are statistically } \\
\text { significant at the } 5 \% \text { level of significance }\end{array}$} & & \\
\hline
\end{tabular}

Cognitive skills

$P V$ - peripheral vision MOT-multiple objects tracking $D C$ - detail recognition TMA - time movement anticipation REC.T. - recognition time
Game skills

SO - spatial orientation

REL.T. - release time

$V C$ - verbal communication

$L O L$ - looking for open lanes

$C D$ - correct decision

Partial correlations can be interpreted as linear dependencies of one variable on another while eliminating effects of other variables. The chart below illustrates e.g. a strong positive dependency between spatial orientation and multiple objects tracking without the influence of other variables. Similarly, a strong dependency can be observed between correct decision and 


\section{$4^{\text {th }}$ International Conference on Advanced Research in Teaching and Education}

looking for open lanes. Key variables are also visible in the chart, as they are in the middle of it.

Chart 4 - Regularized partial correlation network

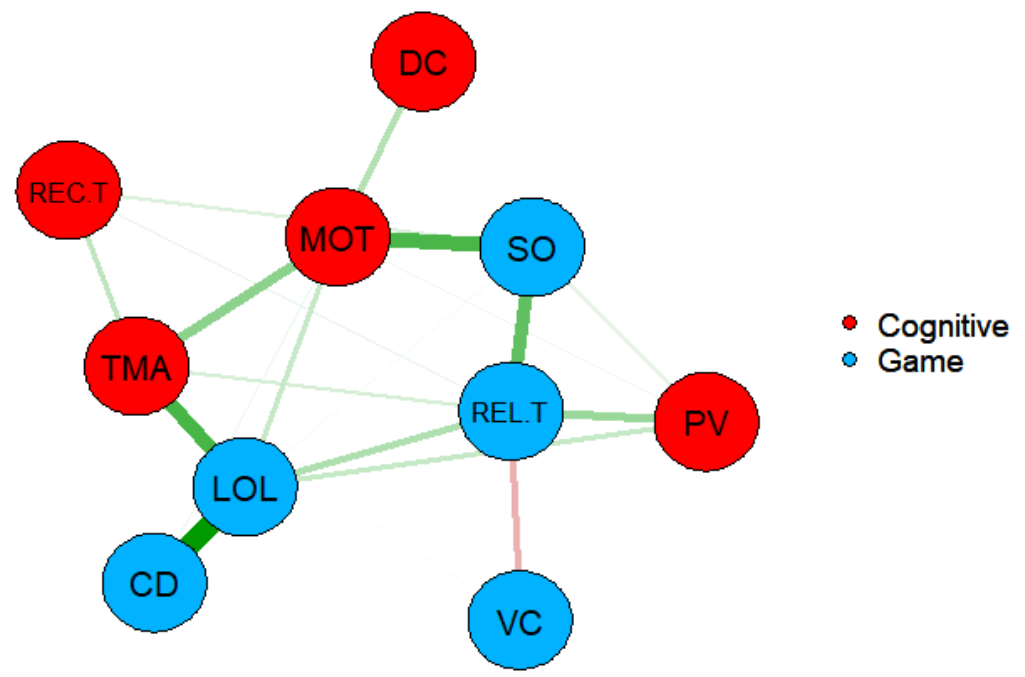

Cognitive skills

Game skills

$P V-$ peripheral vision

MOT-multiple objects tracking

$D C$ - detail recognition

TMA - time movement anticipation

REC.T. - recognition time
SO - spatial orientation

REL.T. - release time

$V C$ - verbal communication

$L O L$ - looking for open lanes

$C D$ - correct decision

\subsubsection{Centrality indices}

Variables highlighted in yellow in the chart below can be considered as key variables because of their high centrality index. Three of them are game skills (release time, spatial orientation, looking for open lanes) and two are cognitive skills (time movement anticipation and multiple objects tracking). Based on this fact, we can state that it is possible to use virtual reality as a training tool for ice hockey-specific training, especially for detecting ice hockey-specific thinking.

Chart 5 - Centrality indices

$\begin{array}{lrrr} & \text { Strenght } & \text { Closeness } & \text { Betweenness } \\ \text { Release time } & 0,788455 & 0,01109251 & 26 \\ \text { Spatial orientation } & 0,666901 & 0,01090089 & 12 \\ \text { Verbal communication } & 0,133927 & 0,00655126 & 0 \\ \text { Looking for open lanes } & 1,045073 & 0,0111882 & 28 \\ \text { Correct decision } & 0,445906 & 0,00920896 & 0 \\ \text { Detail recognition } & 0,123624 & 0,00658846 & 0 \\ \text { Rozpoznavaci_cas } & 0,20236 & 0,00606698 & 0 \\ \text { Recognition time } & 0,667313 & 0,0111291 & 22 \\ \text { Multiple objects tracking } & 0,75366 & 0,01148527 & 18 \\ \text { Peripheral vision } & 0,327504 & 0,00796741 & 0\end{array}$




\section{$4^{\text {th }}$ International Conference on Advanced Research in Teaching and Education}

Chart 6-Key variables

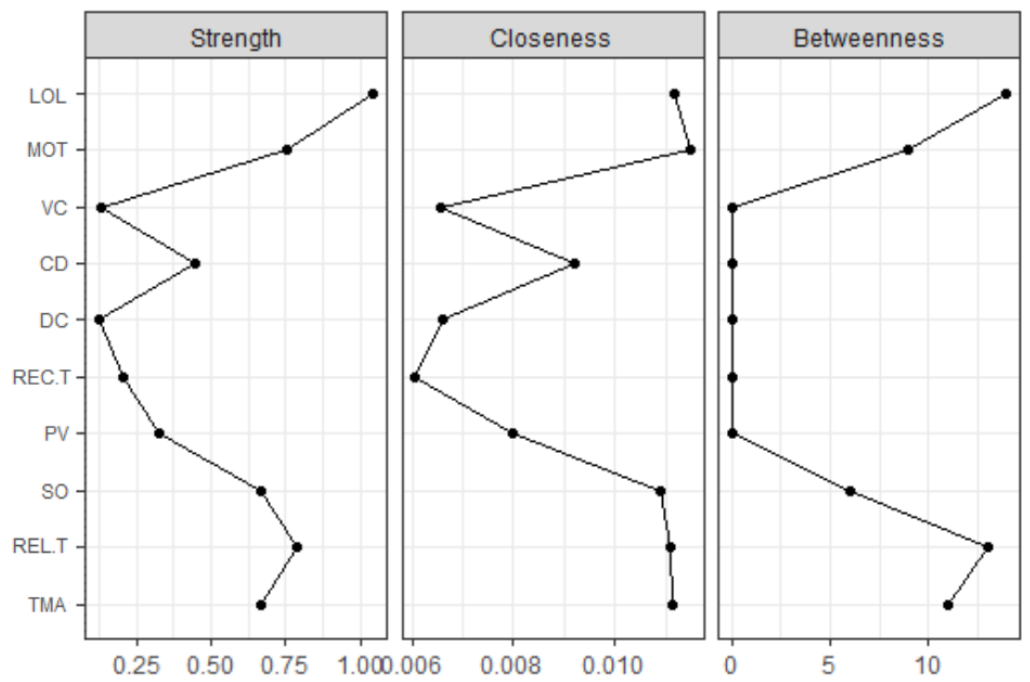

\subsection{Discussion}

Moderate relationships were identified in four main variables, and a strong relationship in one correlation. Due to the results above, we can say that the level of cognitive skills affects ice hocey-specific game skills and activities. Thus, cognitive skills training can improve game skills as well. Four strong relationships between game skills and cognitive skills were found, which implies that cognitive skills affect game skills, and vice versa. A well-timed and accurate pass of a player is based on peripheral vision, spatial orientation, multiple objects tracking and time movement anticipation. All these factors also affect the time to play the puck or shooting speed. If a player is able to correctly and timely evaluate the viability of a pass or a shot, they can become very successful. While eliminating the influence of other variables, a strong positive dependency was found between spatial orientation and multiple objects tracking. In the same way (free from external effects), we can observe a strong dependency between correct decision and looking for open lanes.

The results showed five main and key variables in total, three being game skills - release time, spatial orientation and looking for open lanes, and two being cognitive skills - time movement anticipation and multiple objects tracking.

\section{Conclusion}

\section{Acknowledgment}

The research evaluation, which stems from the aim of this work, proved that the variables determining a specific ice hockey thinking were operationalized as main variables in virtual reality. These main variables then consist of selected game skills, cognitive skills and their partial variables. The results also made clear that moderate and strong relationships were found across all levels of variables. Based on the results, it can be said that virtual reality can be used as a training tool for ice hockey players, especially for developing cognitive skills, which then 


\section{$4^{\text {th }}$ International Conference on Advanced Research in Teaching and Education}

have a positive effect on ice hockey-specific game skills. Virtual reality also enables to measure and determine player's ice hockey intelligence and maturity.

\section{References}

BIDEAU et al. (2003) Real handbal goalkeeper vs. virtual handbal thower. Teleoperators and virtual environments, vol. 12, no. 4, p. 411.421.

BIDEAU, B. et al. (2010) Using virtual reality to analyze sports performance. IEEE Computer Graphics and Applications, vol. 30, Issue 2, p. 14-21.

BOSSARD et al. (2011) Analyze soccer players decision making during training to develop a virtual soccer player model. eJRIEPS, vol. 23, p. 124-151.

CRAIG et al. (2006) Judging where a ball will go: The case of curved free kicks in football. Naturwissenschaften, vol. 93, no. 2, p. 97-101.

CUPERUS A. et al. (2016). Virtual reality replays of sports performance: Effects on memory, feeling of competence, and performace. Learning and motivation, Issue 56, p. 48-52.

De LOOR et al. (2008), Interactive co-construction o study dynamical collaborative situations. Paper presented at the virtual reality international konference, Laval, France.

MURRAY E. G. et al. (2015). The effects of the presence of others during a rowing exercise in a virtual reality environment. Psychology of sport and exercise, vol. 22, p. 328-336.

PASCO, D. (2013), The potential of using virtual reality technology in physical activity settings. National association for kinesiology in higher education (NAKHE), vol. 65, Issue 4, p. 429.

RULÍK, A. Možnosti virtuální reality jako tréninkového prostředku ve sportovních hrách - na př́kladu vybrané sportovní hry. Praha, 2020. Bakalářská práce. Univerzita Karlova. Fakulta tělesné výchovy a sportu. Katedra pedagogicky, psychologie a didaktiky TV a sportu. Vedoucí práce doc. PaedDr. Tomáš Perič, Ph.D.

VIGNAIS et al. (2015), Which technology to investigate visual perception in sport: video vs. virtual reality. Human movement science, Issue 39, p. 12-26. 